\title{
The Incidence of Common Respiratory Viruses During the COVID-19 Pandemic: Results from the Louisville COVID-19 Epidemiology Study
}

\author{
Brian C. Bohn ${ }^{1 *}$, PharmD, BCIDP; Ashley M. Wilde ${ }^{1}$, PharmD, BCPS-AQ ID; Sarah E. Moore ${ }^{1}$, PharmD; Matthew Song ${ }^{1}$, PharmD, BCIDP; \\ Clayton J. Patross ${ }^{1}$, PharmD, BCPS; Alan D. Junkins ${ }^{2}$, PhD, D(ABMM); Paul S. Schulz ${ }^{3}, M D ;$ Julio A. Ramirez ${ }^{4}$, MD; and the Center of \\ Excellence for Research in Infectious Diseases (CERID) COVID-19 Study Group
}

${ }^{1}$ Norton Pharmacy Services, Norton Healthcare, Louisville, KY, USA; ${ }^{2}$ Department of Microbiology, Norton Healthcare, Louisville, KY, USA; ${ }^{3}$ Norton Infectious Diseases Specialists, Norton Healthcare, Louisville, KY, USA; ${ }^{4}$ Division of Infectious Diseases, University of Louisville School of Medicine, Louisville, KY, USA

*brian.bohn@nortonhealthcare.org

Recommended Citation: Bohn BC, Wilde AM, Moore SE, et al. The incidence of common respiratory viruses during the COVID-19 pandemic: Results from the Louisville COVID-19 Epidemiology Study. Univ Louisville J Respir Infect 2020; 4(1):Article 58. doi: 10.18297/jri/vol4/iss1/58.

\begin{abstract}
Introduction: Social distancing has been utilized during the COVID-19 pandemic to reduce the spread of SARS-CoV-2; it is also expected to reduce the spread of common respiratory viruses.

Methods: This retrospective, descriptive study assessed the rate of positivity of common respiratory viruses from a commercially available respiratory pathogen panel across a fivehospital health system during four-week periods within March to April of 2019 and 2020.
\end{abstract}

Results: During the four-week period in 2019, the percent positivity of common respiratory viruses from week 1 to week 4 decreased from 6 to $32 \%$ among the four included viruses. In the comparator period in 2020, a decrease ranging from 74 to $100 \%$ was observed from week 1 to week 4 .

Conclusions: These data indicate that the social distancing efforts implemented in Louisville, Kentucky, may be associated with a decrease in incidence of common respiratory viruses. This decrease in positivity of common respiratory viruses may serve as a surrogate marker for the effect of social distancing on the transmission of SARS-CoV-2.

\section{Introduction}

Social distancing has become a key intervention in preventing the spread of SARS-CoV-2 during the COVID19 pandemic. [1, 2] Throughout March and April of 2020 several interventions aimed at reducing the spread of SARS-CoV-2 have been implemented by national, state, and local governments in a stepwise manner. In Louisville, Kentucky, these include limits on public gatherings (March 11), closure of schools (March 12), closure of non-essential businesses (March 23), and more.[3-5] We hypothesize that these interventions, which were intended to address the current pandemic, would have a significant impact on the droplet transmission of common respiratory virus including influenza, respiratory syncytial virus (RSV), rhinovirus, and common coronaviruses (HKU1, NL63, 229E, and OC43).[6] The objective of this study is to assess the effect of social distancing on the incidence of common respiratory viruses as a surrogate marker for the reduction in transmission of SARS-CoV-2.

\section{Methods}

This was a retrospective, descriptive study examining the incidence of selected community respiratory viruses (influenza, RSV, rhinovirus, and common coronaviruses) detected by a multiplex molecular respiratory viral panel between March 10 to April 6, 2019, and March 8 to April 4, 2020, within the Norton Healthcare health-system. Norton Healthcare consists of five hospitals with over 1800 licensed beds, immediate care centers, and ambulatory medical practices throughout Louisville, Kentucky. A commercially available respiratory pathogen panel (RPP) performed in the system's centralized microbiology laboratory is utilized to identify the previously listed common respiratory viruses. This panel is available year-round and can be ordered by any physician or advanced practice provider for work-up of suspected respiratory illnesses in inpatient and outpatient settings. During the study period all RPP results were recorded and a weekly percent positivity rate for each of the included common respiratory viruses was calculated and plotted on a line graph for 


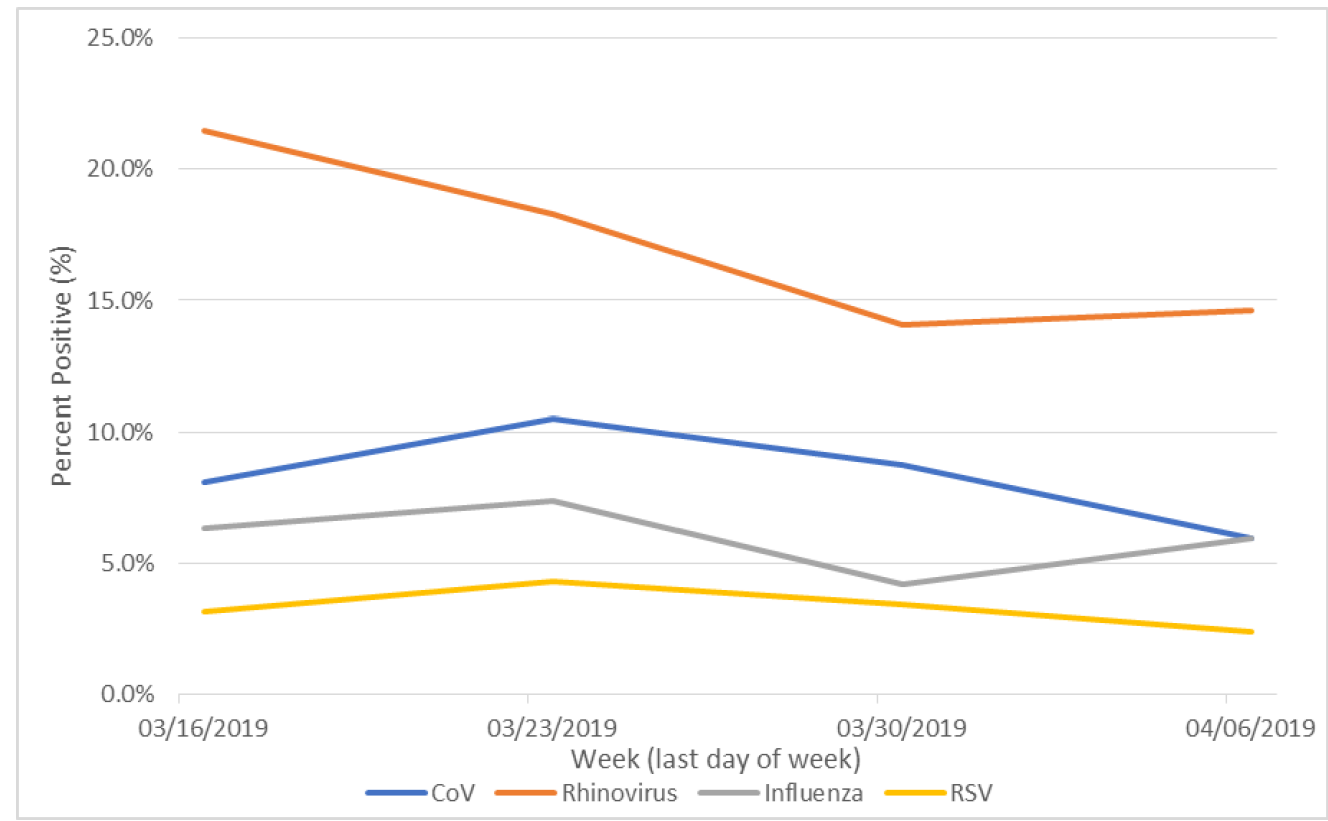

Figure 1. Incidence of common respiratory viruses in a four week period in 2019. Abbreviations: CoV, Coronaviruses (HKU1, NL63, 229E, and OC43); RSV, respiratory syncytial virus.

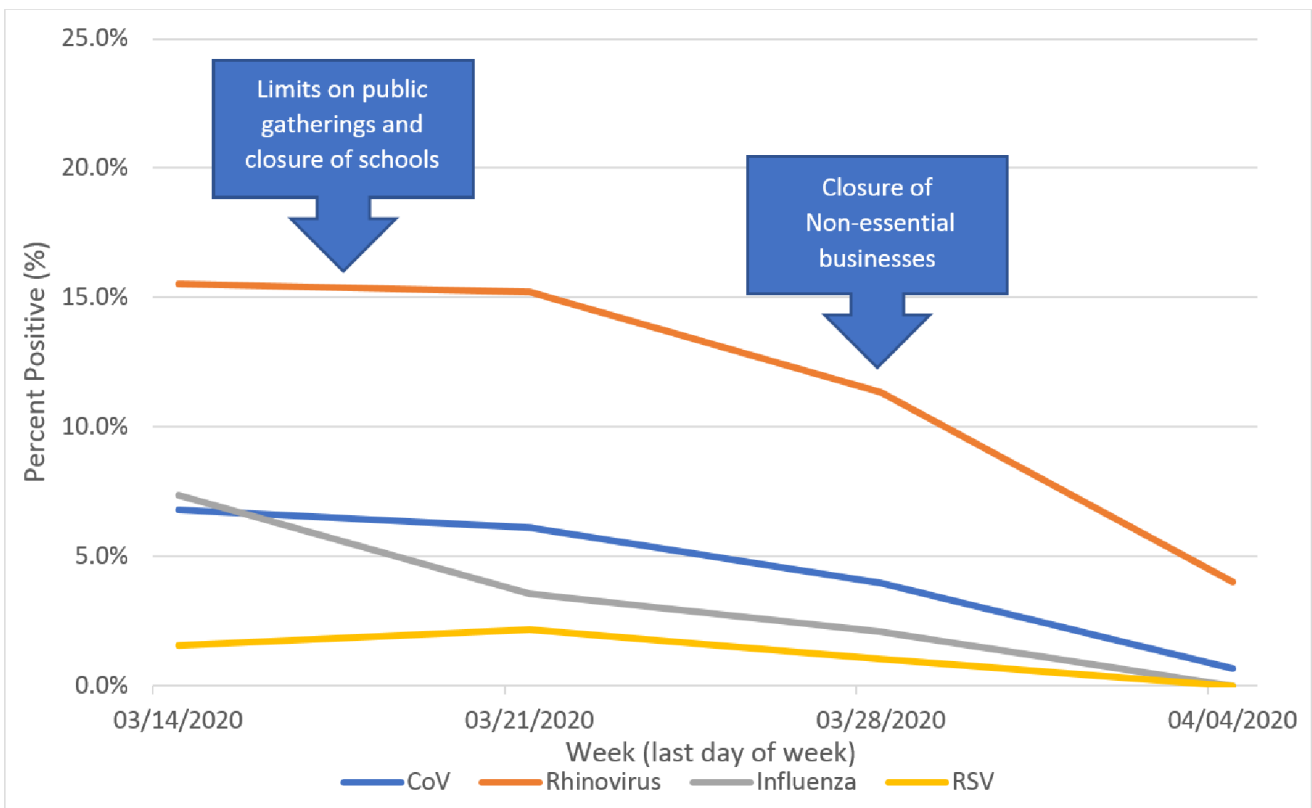

Figure 2. Incidence of common respiratory viruses in a four week period in 2020. Abbreviations: CoV, Coronaviruses (HKU1, NL63, 229E, and OC43); RSV, respiratory syncytial virus. 


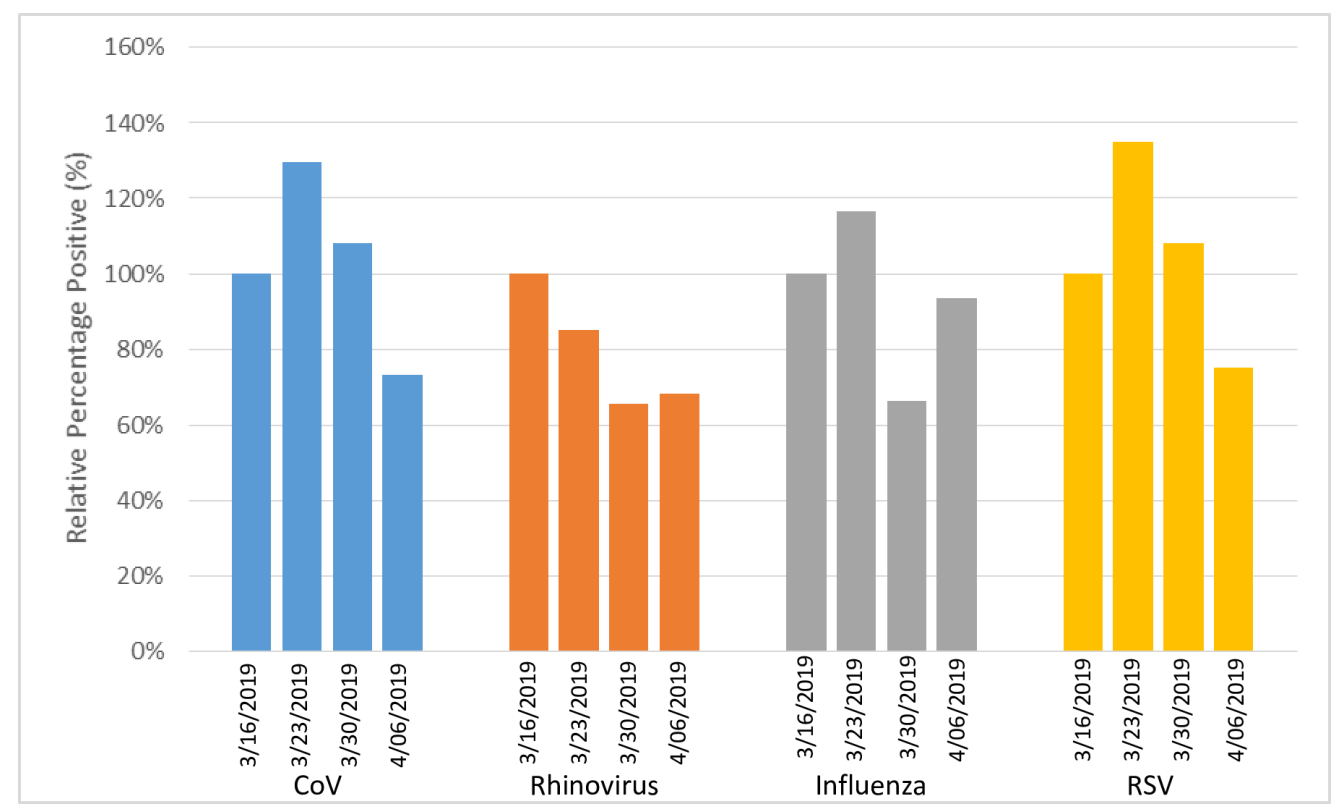

Figure 3. Percentage positivity relative to baseline in the four week period from 2019. Abbreviations: CoV, Coronaviruses (HKU1, NL63, 229E, and OC43); RSV, respiratory syncytial virus.

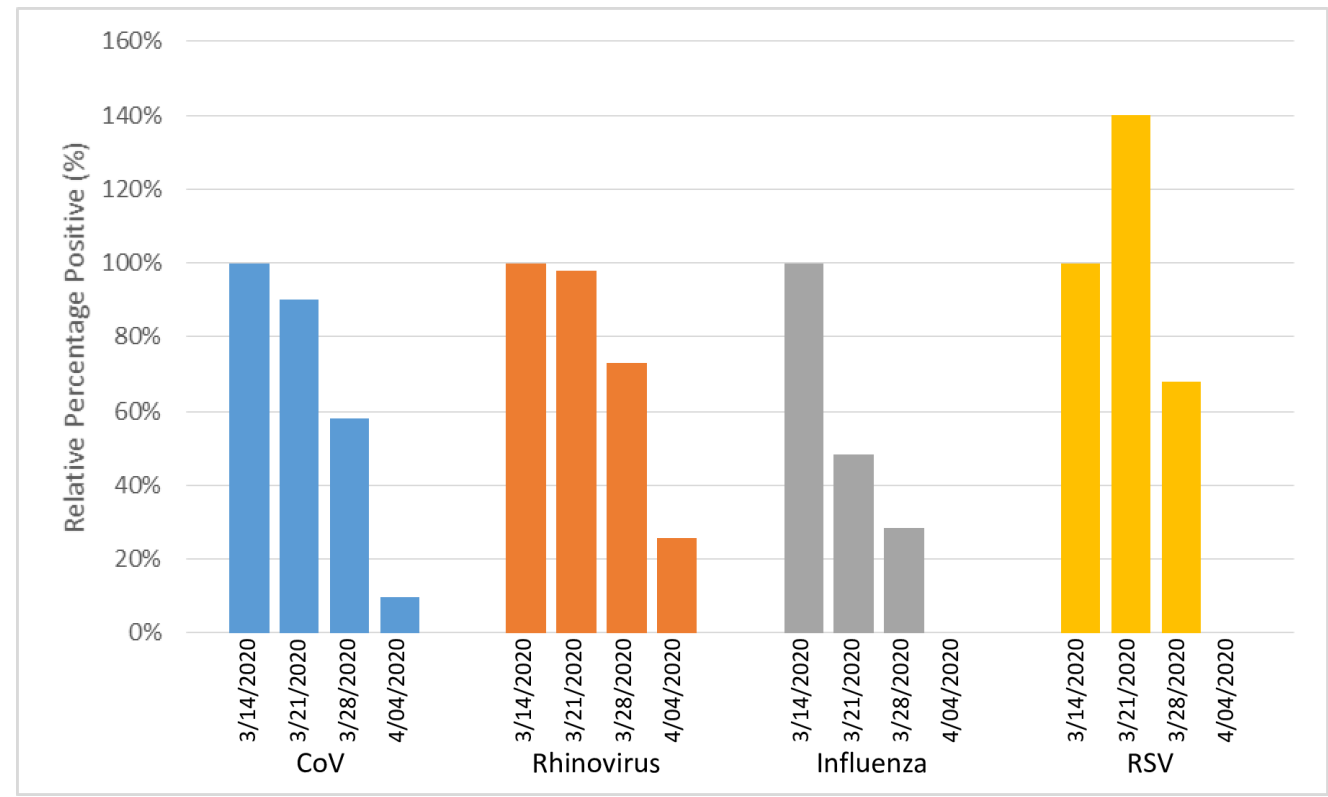

Figure 4. Percentage positivity relative to baseline in the four week period from 2020. Abbreviations: CoV, Coronaviruses (HKU1, NL63, 229E, and OC43); RSV, respiratory syncytial virus. 
each week.

\section{Results}

An average of 264 RPPs per week was obtained during the study period in 2019 and an average of 388 per week was obtained in 2020. There was no consistent trend in the incidence of common respiratory viruses during the four-week period in 2019 (Figure 1). In contrast, incidence of all common respiratory viruses showed a sharp decline over the same period in 2020 (Figure 2). The percentage decrease for common coronaviruses from weeks one to four in 2019 was $27 \%$ compared to $90 \%$ in 2020 . The respective decreases were $32 \%$ in 2019 and $74 \%$ in 2020 for rhinovirus, $6 \%$ in 2019 and $100 \%$ in 2020 for influenza, and $25 \%$ in 2019 and $100 \%$ in 2020 for RSV (Figures 3 and 4 ).

\section{Discussion}

These data display a significant decrease in the incidence of common respiratory virus detected by the RPP starting on the week of March 22, 2020. While there were decreases noted from week to week among the different common respiratory viruses in 2019, there was no consistent decline across all noted common respiratory viruses as seen in 2020. Furthermore, the percentage decreases across the four-week period observed in 2020 were a significantly greater magnitude, ranging from $74 \%$ to $100 \%$, than those observed in 2019 which ranged from $6 \%$ to $32 \%$.

The observed decrease in common respiratory viruses in 2020 coincided with the closure of all non-essential

Received: May 14, 2020

Accepted: August 7, 2020

Published: August 25, 2020

Copyright: (c) 2022 The author(s). This original article is brought to you for free and open access by ThinkIR: The University of Louisville's Institutional Repository. For more information, please contact thinkir@louisville.edu. This article is retail businesses in Kentucky, which was the most significant step to date in social distancing. The noted decline in incidence of common respiratory viruses in the third and fourth weeks of these data suggest that the implemented social distancing efforts had an impact on common respiratory virus transmission. These data also emphasize the importance of avoiding contact with others when ill in pandemic and non-pandemic scenarios.

While these data highlight the effect of social distancing on common respiratory viruses, it is expected that efforts also led to a reduction in SARS-COV-2 transmission as intended. As of April 20, 2020, Kentucky had fewer reported COVID-19 cases than all but one (West Virginia) of the seven states it borders.[7] Without the effect of the social distancing efforts enacted swiftly in Kentucky, it is likely that the case burden would be significantly higher and may have resulted in the overwhelming the healthcare system.

In conclusion, the rate of positivity on the RPP of a select group of common respiratory viruses declined simultaneously with the implementation of strict social distancing guidance in Kentucky. The decline occurred more precipitously in 2020 than it did over the same time period in 2019, and was demonstrable in all of the viruses studied, suggesting that the demonstrated decline was likely not due to an expected end to the respiratory virus season, but was instead a result of factors unique to 2020. These data indicate the potential effectiveness of social distancing in reducing common respiratory virus incidence and thus may serve as a surrogate marker for efficacy in reducing the transmission of SARS-CoV-2 as well.

\section{References}

1. Centers for Disease Control and Prevention. Social distancing: Keep a safe distance to slow the spread. Available at: https://www.cdc.gov/coronavirus/2019-ncov/preventgetting-sick/social-distancing.html. Accessed 1 August 2020.

2. Kentucky Public Health. Novel coronavirus (COVID19) guidance for residents of Kentucky. Available at: https://chfs.ky.gov/agencies/dph/covid19/ distributed under the terms of the Creative Commons Attribution 4.0 International License (CC BY 4.0), which permits unrestricted use, distribution, and reproduction in any medium, provided the original author and source are credited.

Funding Source: The author(s) received no specific funding for this work.

Conflict of Interest: All authors declared no conflict of interest in relation to the main objective of this work. guidanceforkentuckyresidentscovid19.pdf. Accessed 1 August 2020.

3. Office of the Governor, Commonwealth of Kentucky. Gov. Beshear provides guidance on public events, schools, prisons as state continues preparations and response to COVID-19. Online, 2020.

4. Office of the Governor, Commonwealth of Kentucky. Gov. 
Beshear recommends public, private schools ceasing inperson classes in response to COVID-19. Online, 2020.

5. Office of the Governor Commonwealth of Kentucky. Gov. Beshear issues new guidance to help halt the spread of COVID-19. Online, 2020.

6. Mandell, Douglas, and Bennett's Principles and Practice of Infectious Diseases. Eighth ed. Philadelphia, PA: Elsevier/Saunders, 2014.

7. Centers for Disease Control and Prevention. Cases of coronavirus disease (COVID-19) in the U.S. Available at: https://www.cdc.gov/coronavirus/2019-ncov/casesupdates/cases-in-us.html. Accessed 20 April 2020.

\section{Appendix: CERID COVID-19 Study Group}

Available upon request. 